\title{
'We had to take a hammer to get some roots out' - experiences, motivations and challenges among volunteer dentists: a qualitative study
}

\author{
Saulo Gamarra, *1,2 Kate Bärnighausen, ${ }^{1,3}$ Jonas Wachinger ${ }^{1}$ and Shannon A. McMahon ${ }^{1,4}$
}

\section{Key points}

Individuals volunteering for dental care missions have a broad spectrum of motivations, including to engage in humanitarian work, but also a desire for tourism and to enhance their own skillset.
Once in the field, volunteers face several barriers which prevent them from delivering the care they envisioned, including limited resources, high patient load, peri- and post-operative complications, and a feeling of futility.
Volunteers recommended more comprehensive information and training before volunteer missions as a means to manage expectations, build capacity and support successful volunteering missions.

\begin{abstract}
Objectives To address a gap in the literature by examining the experiences, motivations and challenges among volunteer dentists engaged in short-term missions to low- and middle-income countries.

Methods In-depth interviews among volunteer dentists $(n=20)$ who had provided voluntary dental care in low- or middleincome countries within the preceding five years. Interviews lasted on average 55 minutes and were recorded, transcribed and analysed using NVivo. Routine debriefings complemented analysis. COREQ principles guided this research.

Results Motivations to volunteer included: exposure to new dental challenges (enhancing competence); discovering a new setting (tourism); and enhancing the lives of clients (humanitarianism). Volunteers enjoyed undertaking new tasks and developing new skills, but were burdened by a high patient load, challenging clinical conditions, peri- and post-operative complications, and a concern that their work was not addressing root causes of inadequate access to basic dental care. Respondents recommended that more information regarding the vision, equipment status, armamentarium and dental supplies be made available pre-departure, and that more dental schools include training on global oral health. Such measures could facilitate volunteers' abilities to provide care while also enhancing their personal and professional development. Creating an appropriate, sizable and competent capacity-building programme for local dentists was described as essential.
\end{abstract}

\section{Introduction}

Oral diseases represent a neglected area of research within the public health and global health discourse. ${ }^{1,2}$ Although largely preventable and treatable, oral disease affects approximately 3.5 billion people globally, increasing health and economic burdens while significantly decreasing quality of life. ${ }^{3}$ With populations in low- and middleincome countries (LMICs) disproportionately

${ }^{1}$ Heidelberg Institute of Global Health, Faculty of Medicine, University of Heidelberg, Heidelberg, Germany; ${ }^{2}$ Dentists Serving the Poor - Latin America (DSP-LA), Peru:

${ }^{3}$ University of the Witwatersrand School of Public Health, Johannesburg, South Africa; ${ }^{4}$ Department of International Health, Johns Hopkins Bloomberg School of Public Health, 615 North Wolfe Street, Baltimore, Maryland, USA.

*Correspondence to: Saulo Gamarra

Email address: saulogamarra@hotmail.com

Refereed Paper.

Accepted 17 November 2020

https://doi.org/10.1038/s41415-021-3222-6 affected, ${ }^{4,5}$ oral disease highlights the widespread poverty and inequalities experienced by those least able to access care. ${ }^{1,3,6,7}$ Accessible, integrated, inclusive and sustained oral health investments that tackle the broad social determinants of poor oral health are critical if the needs of billions of individuals are to be addressed. ${ }^{3,7}$

However, as these broad changes are awaited, organisations and dental volunteers have sought to address gaps in the availability of oral healthcare in many LMIC settings. ${ }^{8}$ Dental volunteering, like medical volunteering generally, is typically organised by academic or non-academic medical centres, nongovernmental organisations (NGOs) and religious or community groups. ${ }^{9,10}$ The most common model of dental volunteering entails short-term, clinical care.

This approach has been criticised in recent years on the grounds of its sustainability, effectiveness, accountability and ethical appropriateness. ${ }^{7,11,12,13,14}$ The impact of volunteer dental engagement on oral health at the population level remains difficult to measure but is presumably limited, ${ }^{15}$ and charitable approaches are unlikely to change the fundamental inequalities of access and dependency outlined above. ${ }^{7}$ However, evidence from dental volunteering research highlights how volunteering can make valuable contributions to global oral health while simultaneously enhancing the professional acumen and personal enrichment of those undertaking the work. ${ }^{16,17}$

Despite the continued expansion of dental volunteering, ${ }^{18}$ there is surprisingly little data (with some notable case study exceptions) ${ }^{19,20}$ regarding why dentists undertake such efforts, what experiences they have while volunteering, and how they would recommend that programmes be improved. To address these gaps, we conducted a qualitative study to gain an understanding of motivations for and experiences with dental volunteering. 


\section{Methods}

\section{Study team}

The lead author (SG) completed this work as part of a master's thesis in international health, supervised by the senior author (SM). $S G$ received formal training on qualitative theory and methods before and throughout the data collection process. All co-authors have experience in qualitative research.

\section{Study procedures}

SG used snowball sampling ${ }^{21}$ to invite a total of 50 dental volunteers (DVs) via e-mail to participate in this study. Those initially invited were identified based on their engagement in informal networks of previous dental volunteers. After screening of those DVs who signalled interest to participate and who met the inclusion criteria (they originated from a high-income setting, had worked for at least two years as a dentist and had worked as DVs within the preceding five years in an LMIC), informed consent was obtained and the interview was conducted in person or via a video call platform of the participant's choosing. Interviews focused on notions of motivations for volunteering, as well as experiences and challenges faced while volunteering. At the close of interviews, respondents were asked to provide guidance on others who could be interviewed and these individuals were also contacted..$^{21}$ Daily debriefing sessions ${ }^{22}$ were conducted throughout data collection between SM and SG to discuss and triangulate findings and refine lines of inquiry. Interviews continued until saturation of themes was reached. ${ }^{23}$ All interviews were recorded and transcribed verbatim. The ethical review board at the Medical Faculty, Heidelberg University, Germany approved this study (S-232/2018).

\section{Data analysis}

We analysed the data guided by the tenets of grounded theory, ${ }^{24}$ which allows for inductively conceptualising and organising the data. We familiarised ourselves with the dataset and developed a codebook based on emerging themes. Codes were shared among co-authors and compared with the findings that emerged in systematic debriefings. The final codebook was then inductively and deductively applied to the dataset using NVivo 12.

When analysing the data, a social ecological model $^{25}$ emerged as a means to arrange how motivations, barriers and facilitators operated across three levels: organisational, interpersonal

Table 1 Respondent demographics $(n=20)$

\begin{tabular}{l|l} 
Characteristic & N (\%) \\
\hline Gender & $9(45)$ \\
\hline Female & $11(55)$ \\
\hline Male & \multicolumn{2}{l}{} \\
\hline Age (years) & $12(60)$ \\
\hline $25-35$ & $2(10)$ \\
\hline $36-45$ & $1(5)$ \\
\hline $46-55$ & $2(10)$ \\
\hline $56-65$ & $3(15)$ \\
\hline$>65$ &
\end{tabular}

\section{Region of origin}

\begin{tabular}{l|l}
\hline America & $2(10)$ \\
\hline Europe & $14(70)$ \\
\hline Asia & $1(5)$ \\
\hline Australia & $3(15)$ \\
\hline Marital status & $13(65)$ \\
\hline Single & $6(30)$ \\
\hline Married & $1(5)$
\end{tabular}

Years as dentist

\begin{tabular}{l|l}
\hline $1-10$ & $14(70)$ \\
\hline $11-20$ & $0(0)$ \\
\hline $21-30$ & $2(10)$ \\
\hline$>31$ & $4(20)$ \\
\hline
\end{tabular}

\section{Number of dental volunteer missions}

\begin{tabular}{l|l}
\hline $1-5$ missions & $14(70)$ \\
\hline $6-10$ missions & $4(20)$ \\
\hline $11-15$ missions & $2(10)$ \\
\hline
\end{tabular}

and individual. This arrangement allowed us to appreciate how the behaviour and experiences of the individual DV is often guided by the broader context within which they operate.

\section{Reflexivity}

SG, a dentist, is engaged personally and professionally in the topic of dentistry both in his work within rural and underserved communities, and as a volunteer who has served on dental missions in LMICs. During debriefings, the lead author and senior author SM (a qualitative researcher who has no background in dentistry) examined biases, compared insights related to data gleaned during interviews, and discussed how to seek out disconfirming cases during sampling to ensure that - despite the snowball approach - those who have never worked with the first author would also be included in the study.

\section{Results}

Respondents $(n=20)$ had performed volunteer dental missions in Africa, Asia and Latin America. Respondents were between 26 and 73 years old (median of 39.85), and their professional dental experience ranged from 3-43 years. Individual dental missions lasted one to six weeks, with a median of three weeks. All respondents had been on a dental mission within the preceding four years (Table 1). Missions 
Table 2 Facilitators for and barriers to volunteering (LMICs = low- and middle-income countries)

\begin{tabular}{|c|c|c|}
\hline Level & Facilitators for volunteering & Barriers faced \\
\hline Organisational level & $\begin{array}{l}\text { Clear and comprehensive information: } \\
\text { 'Ilooked at the information and the more I looked into it the } \\
\text { more I got enthusiastic about working with them' } \\
\text { Characteristics of the respective organisation (for example, } \\
\text { emphasis on sustainability, religious affiliation etc): } \\
\text { 'Before I work with any organisation, I look at why they are } \\
\text { doing what they are doing' } \\
\text { Emphasis on volunteering in dental schools: } \\
\text { 'When I was an undergraduate dental student at [university], } \\
\text { part of the degree was to do an elective as a volunteer' } \\
\text { Good equipment and preparatory information: } \\
\text { 'We are equipped to do everything even at a high level, the } \\
\text { clinic is very well equipped' }\end{array}$ & $\begin{array}{l}\text { Organisation's enrolment system for volunteers: } \\
\text { 'I do understand that there was quite a lot of checks and things like that and it takes } \\
\text { a little bit of time to get everything together...but I can see that could be a potential } \\
\text { barrier for people to not volunteer because of all of these things involved' } \\
\text { Adapting to a new setting: } \\
\text { 'I can be a bit apprehensive when I am just aware it's going to be different people } \\
\text { different set-up' } \\
\text { Frustration on oral health education and prevention in LMICs: } \\
\text { 'So if people knew more what food or drinks cause decay and if they have less of that } \\
\text { they would have less decay' } \\
\text { Lack of resources: } \\
\text { 'We had to take a hammer to get some roots out, so it was very primitive and very dirty' } \\
\text { High patient load: } \\
\text { 'We weren't able to treat all the dental need, there was just too much need' } \\
\text { Patients' clinical conditions: } \\
\text { 'IIt] can be a little bit overwhelming, being presented with cases that are quite a bit } \\
\text { more extreme, a bit more like life-threatening' } \\
\text { Inappropriate clinical actions: } \\
\text { 'There were none dentist [sic], but engineers pulling out teeth' }\end{array}$ \\
\hline Interpersonal level & $\begin{array}{l}\text { Teamwork and common purpose: } \\
\text { 'We can't do it without a team work' } \\
\text { Humanitarianism in action: } \\
\text { 'I feel like I'm giving back to the world' } \\
\text { Strong (gratifying) patient cooperation: } \\
\text { '[We had] brilliant cooperation [with our clients], often better } \\
\text { than cooperation in my own country the UK' }\end{array}$ & $\begin{array}{l}\text { Communication with patients: } \\
\text { 'I think communication was definitely the most difficult' } \\
\text { Lack of experience: } \\
\text { 'On every campaign we hear things like I've never seen this before' }\end{array}$ \\
\hline Individual level & $\begin{array}{l}\text { Opportunity to gain professional experience: } \\
\text { 'Gaining experience dealing with difficult cases in a completely } \\
\text { different environment just...adds to your skillset as a dentist' } \\
\text { Tourism: } \\
\text { 'I wanted to explore a different way of working compared to } \\
\text { my now day to day' } \\
\text { Desire to gain perspective: } \\
\text { 'I think it made me appreciate that we have a good dental } \\
\text { system in Norway' } \\
\text { Desire to feel the utility of one's skillset: } \\
\text { 'I think from the personal and self-point of view, [it was] } \\
\text { an extremely rewarding and eye opening...and it was an } \\
\text { amazing experience at the time' }\end{array}$ & $\begin{array}{l}\text { Short time in the field: } \\
\text { 'I think the hardest part is that you cannot do any follow-up' } \\
\text { Futility: } \\
\text { '[My work] is only a drop of water on a hot stone' } \\
\text { Decision-making: } \\
\text { 'It was difficult to decide to extract teeth, which potentially would be technically } \\
\text { savable, in our home country' }\end{array}$ \\
\hline
\end{tabular}

varied in terms of size, duration and focus, with a majority of participants preferring missions that aligned with their personal beliefs (for example, undertaken by Christian organisations) and focused on sustainable activities (for example, capacity-building for local dentists).

We begin by highlighting the type of care DVs provided on their missions. We then present key motivations for volunteering and dominant barriers encountered during volunteering (see Table 2). Finally, we summarise respondentdriven recommendations on how to improve dental volunteering processes and missions (see Table 3).

\section{Care provided}

Respondents described conducting routine dental care such as exodontia (including surgical extractions), dental cleaning and restorative work. They also described larger oral surgeries (such as cyst and tumour enucleations and jaw sequestrectomies), as well as procedures including root canal treatments and dentures.

\section{Motivations for joining and continuing} volunteer dental missions

Most respondents said that they joined dental missions after interacting directly or indirectly with another dentist who had volunteered (for example, listening to a dentist speak or reading about a DV's experiences in a book, magazine or blog), or learning about the opportunity in dental school (for example, via word of mouth, or a volunteering elective). Key motivations for volunteering were humanitarianism, volunteerism and a bolstered sense of selfworth. DVs often said they wanted to 'better help improve people's dental health', to 'help someone who has been suffering and in pain for a long time' and 'to give back to the world'. This was described as an important end unto itself, but also as a means to feel accomplished 
and as a valuable contributor, both in a global sense and in one's own profession. Several respondents described a 'sense of satisfaction' and purpose while volunteering. Respondents described feeling a 'rush of happiness [...] like an addiction' or a thrill after engaging with patients who were exceptionally grateful for care, and who demonstrated their appreciation via hugs, tears of joy and 'thank you' cards. Several dentists contrasted this with patients in their home country who resent visiting a dentist or 'who think they know everything' and quote Google and internet websites rather than relying on professional dentists.

Along with describing humanitarianism as a motivator, some respondents also described a desire to see another part of the world and to gain technical skills or experiences that they would not likely encounter in their home settings or would only read about in books. Several respondents described the routine of their daily professional lives and contrasted this with what they saw (or had envisioned seeing) while volunteering overseas. As one respondent said, ' $m y$ life had become a lot about routine' and another described how they wanted to push themselves to think beyond 'just me, my own success and my own happiness'.

Volunteers described the process of enrolling as relatively straightforward because 'the info about [the volunteer organisation] was easily accessible on the internet'.

\section{Challenges and barriers faced}

In terms of challenges, respondents reported minor concerns or suggestions regarding the processes to enrol in volunteer missions. However, a number of severe challenges were discussed regarding the experiences while volunteering, such as a high volume of clients and the complexity of cases, the lack of resources, and frustration about post-operative complications and clinical decision-making. The number of patients and their respective needs while volunteering was described as 'overwhelming', 'heart-breaking', 'daunting', 'just so much', 'endless' and 'massive'. Several respondents described complex procedures (for example, fixing broken jaws and performing cyst and tumour enucleations, sequestrectomies and extraoral surgery) that challenged them mentally and physically. Less often, respondents also described encountering cases that they 'were never trained to do or had never seen done. Several respondents described their work as an endurance test. One respondent described feeling exhausted,

Table 3 Respondent recommendations

\begin{tabular}{l|l} 
Setting & Recommendations \\
\hline Pre-departure & $\begin{array}{l}\text { Organisations should include comprehensive information on vision, equipment status, } \\
\text { armamentarium and dental supplies on their websites } \\
\text { Organisations should ensure that volunteers have the necessary skills and experiences } \\
\text { needed for the respective mission, and structure teams accordingly } \\
\text { Dental schools should include more courses on global oral health in their curriculum } \\
\text { Volunteers should critically reflect on their own expertise and ability, seek for additional } \\
\text { training wherever possible, and select organisations which provide expertise and } \\
\text { infrastructure fitting their own skill level }\end{array}$ \\
\hline In the field & $\begin{array}{l}\text { Organisations should ensure that teams always include at least one highly experienced } \\
\text { dentist to ensure patients' safety and support for less experienced dentists } \\
\text { Organisations should always include oral health education and prevention measures in } \\
\text { their work in the field, including capacity-building programmes for local dentists } \\
\text { Organisations should have clear protocols and guidelines, both for the mission-related } \\
\text { work as well as the general conduct of volunteers while in the field } \\
\text { Volunteers should be aware of their responsibilities and expertise, both in the context } \\
\text { of their work (only perform procedures they were trained on and seek assistance where } \\
\text { needed) and their role as a foreign volunteer in the field }\end{array}$ \\
\hline Larger context & $\begin{array}{l}\text { Dental volunteering cannot be a sustainable solution to tackle the global challenge of oral } \\
\text { diseases, but has to be seen as contributing to alleviating symptoms }\end{array}$ \\
\hline
\end{tabular}

and then looking at their hands and realising: 'I had calluses from doing so many extractions'. Respondents described needing to turn away or refer patients with life-threatening cases to a local hospital.

Another challenge was a lack of resources such as equipment, instruments and/or dental supplies, and missing infrastructure ranging from $\mathrm{x}$-rays and air pressure or suction machines to water, lights and electricity. Several respondents described challenges of providing care in tropical, sweat-inducing conditions, as well as a lack of familiarity with 'primitive, totally basic' equipment:

- 'We had very primitive dental equipment. We didn't have real air pressure; we didn't have electricity so sometimes the machines didn't work. We just had to work by hand. We had to take a hammer to get some roots out'.

A few respondents described feeling nervous and out of place on their first day due to working in a different place with different people and an unfamiliar set-up. One respondent described the 'hardest part' to be 'not the patients, it's the circumstances in which we treat the patients'. Another challenge involved a lack of translators, or an inability among respondents to effectively communicate with patients, which inhibited respondents' ability to reassure or comfort patients.

A major theme across many respondents was frustration with post-operative complications. Respondents mentioned that unexpected perioperative clinical events could happen during the treatments, largely because patients' oral health was heavily deteriorated and thus presented greater challenges. A recurrent theme was tooth-breaking during extractions, which then required more complicated procedures. Respondents described finding pieces of roots pushed into the sinus, or encountering patients who had received a treatment earlier but then returned to the dental facility in a worsened condition due to infections. The most commonly described post-operative complications were bleedings and dry sockets.

Respondents also described feeling torn about clinical decision-making. A recurring theme was the challenge of choosing a course of action that made sense in a context of resource constraints (where patients lack follow-up care and/or lack access to oral hygiene), but would not be the standard of care in the volunteer's home setting. Respondents often described the difficulty of extracting a tooth when they knew it 'would be technically doable in my home country'. One participant, looking back at the mission, explained the following:

- 'I wasn't really sure exactly what to do... that was one of the hardest cases that I wasn't really sure what to do.

One participant described performing treatments that are not evidence-based dentistry. While bridges are normally made in a dental laboratory under a dentist's supervision, one respondent described making their own bridge: 'I did a composite bridge, so I figured it was going to be okay'. 
Many participants described a sense of futility. Some highlighted that the amount of time spent in a field service was short, which prevented follow-up care and addressing complications. Some respondents shared concerns about sustainability, and emphasised a desire to engage in more trainings among and for locally based dentists, and to undertake outreach in schools or communities about the basics of oral health. One respondent described their several volunteer missions as amounting to nothing more than ' $a$ drop of water on a hot stone', but later added that helping 'perhaps a hundred or two hundred people has its worth'.

Relatively few respondents described missing a spouse or partner and the financial cost of volunteering. One respondent described shortening the duration of their volunteer mission because they felt the hygienic standards were too low and that the director of the programme was 'too authoritarian'.

\section{Recommendations}

Participants expressed a number of recommendations on how to improve preparation for, and the organisation of, dental volunteering missions to reduce barriers and maximise benefits for both patients and volunteers (see Table 3). These included recommendations on how to better organise and prepare missions pre-departure (for example, comprehensive information, better training and realistic skills assessment), how to improve the work in the field (for example, good team management, clear practice guidelines and ethical conduct of volunteers) and that dental volunteering has to be embedded in the broader discourse on how a more sustainable solution for the challenge of global oral health can be achieved.

\section{Discussion}

Our findings highlight the key motivations for engaging in dental volunteerism as: the opportunity to gain exposure to new dental challenges and enhance professional competence; the chance to explore a new setting; and the perception to improve the oral health of individuals with limited access to care. Key challenges DVs faced included a high patient load, complicated clinical conditions, a lack of resources, the complications arising from working in a different setting, and periand post-operative complications.

Similar to other volunteering literature, ${ }^{8,26,27}$ participants in this study volunteer for several reasons, but a central motivation is the humanitarian desire to help others which in turn bolsters DVs' sense of being useful and needed. ${ }^{26}$ Our work resonates with findings from Clary et al. who found that power, selfactualisation, service to society, emotional associations, autonomy and a need for mutual support are motivators for engaging in volunteerism. ${ }^{27}$ This is also mirrored in the importance of sharing knowledge and experience without receiving any monetary or registered professional gain, but instead as a form of giving back to the community. ${ }^{27}$

Our findings align further with extant DV literature highlighting that it improves patients' clinical experiences, the experiences of DVs, and the likelihood of them recommending volunteering to colleagues when DVs feel supported and have adequate resources and a respectful environment. The volunteering experience can be enjoyed, would be recommended to other colleagues and contributes to a better clinical experience for patients. ${ }^{17}$ Real-time feedback from DVs to programme implementers regarding the process and outcomes of volunteering may improve the uptake of interventions by patients as well as the sustainability of services, as both patients and volunteers participate in more inclusive services. ${ }^{17}$

In terms of barriers to volunteering, our study identified a shortage of dental equipment and supplies as major issues, which has also been found in other volunteering settings. ${ }^{28}$ Besides some well-established organisations, many smaller NGOs have limited resources ${ }^{29}$ and some organisations encourage volunteers to bring their own instruments and medical supplies, which are considered essential for general practice. ${ }^{28}$ Furthermore, similar to work by Huchko, ${ }^{30}$ our findings not only acknowledge a lack of resources within many volunteer organisations, but also in the respective host community, where access to water, electricity and equipment needed for the procedures is often limited. While this environment may encourage and train DVs to be more creative in their practice, it may increase risks for patients and their long-term health. ${ }^{31,32}$

We also identified a number of clinical complications that repeatedly occurred in a volunteering setting. As in work by Varghese, we observed haemorrhage, pain, oroantral communication and mandibular fracture as the most common peri-operative complications. $^{33,34}$ Other peri-operative complications described in this paper include bone fragment fractures and tooth fractures, and remaining roots in alveolus. Our study sheds light on how short-term DVs are concerned regarding potential unintended harm caused, as they often leave the field before the patient presents with a complication.

Moreover, some respondents in our study have seen certain clinical cases for the first time while volunteering, and have had difficulties with clinical procedures and the new environment. Holmgren and Benzian note that DVs may not have enough experience, are poorly connected with the local health system and can be tempted to practise outside of their scope of competencies. ${ }^{13}$ DVs may cause additional harm to patients through misdiagnoses, inappropriate treatments and ineffective use of resources, ${ }^{35}$ raising a number of ethical concerns. ${ }^{12}$ To address such concerns, the participants in this study offered a number of recommendations based on their own experiences, including on how to better prepare DVs and how to reduce the risks of them operating outside their own area of expertise or the guidelines of the institutions.

In addition to these ethical concerns, dental volunteering has often been criticised for a lack of sustainability of the help provided. ${ }^{13,36}$ This also emerged as a concern from this study. In this regard, participants' recommendations were in line with the current discourse in the literature that highlights the need for broader social interventions that support the underlying causes of oral disease. While the recommendation of increased investment in short-term oral health education is only to a limited degree supported in the literature, ${ }^{13,37}$ capacity-building programmes for local healthcare professionals are in line with what other authors have described as a promising way forward. ${ }^{13,36}$

Our study has limitations. There may be selection bias, as we employed snowball sampling, which started with respondents who had undertaken work within large NGOs. Different themes might emerge from data collected from DVs with smaller, underresourced NGOs. Additionally, there was no follow-up for people who did not respond to an initial invitation to an interview. Finally, all interviews were conducted in English to overcome language barriers, although English is not the first language of the interviewer nor for some respondents.

Looking ahead, we encourage further research that examines the actual impact 
DVs have on the oral health of beneficiaries both in the short and long term. We also urge research that explores how DVs can be better supported to make clinical decisions that are in the best interests of their patients, given inherent constraints, and research on how to bolster sustainability efforts among volunteer organisations, ${ }^{17}$ which could address a longstanding criticism. . $^{13,14,36}$

\section{Conclusion}

This study highlights the existence of a body of professional dentists eager to volunteer in underserved countries, but whose abilities, expectations and skills may benefit from greater training and mentoring while in the field. We recommend that more emphasis be placed on providing sufficient materials and support for DVs - and on accurately describing the situations that may be encountered - in order for DVs to be better placed to provide care that enhances their personal and professional development while achieving and sustaining improved oral health. Finally, we urge that programmes and interventions to enhance local dental capacity be developed and tested as a means to address sustainability.

\section{Acknowledgements}

We thank respondents who participated in the interviews. We thank Debbie Oken and those who assisted in interview transcription. The authors received no financial support for the research, authorship and/ or publication of this article. The Olympia-MorataProgramm supports co-author Shannon A. McMahon in her position at Heidelberg University.

\section{Conflict of interest}

The authors declare that they have no conflicts of interest.

\section{References}

1. Jin L J, Lamster I B, Greenspan J S, Pitts N B, Scully C, Warnakulasuriya S. Global burden of oral diseases: Emerging concepts, management and interplay with systemic health. Oral Dis 2016; 22: 609-619.

2. Kassebaum N J, Smith A G C, Bernabé E et al. Global, Regional, and National Prevalence, Incidence, and Disability-Adjusted Life Years for Oral Conditions for 195 Countries, 1990-2015: A Systematic Analysis for the Global Burden of Diseases, Injuries, and Risk Factors. J Dent Res 2017; 96: 380-387.

3. Peres M A, Macpherson L M D, Weyant R J et al. Oral diseases: A global public health challenge. Lancet 2019; 394: 249-260.

4. Hosseinpoor A R, Itani L, Petersen P E. Socio-economic inequality in oral healthcare coverage: Results from the World Health Survey. J Dent Res 2012; 91: 275-281.

5. Watt R G, Daly B, Allison P et al. Ending the neglect of global oral health: Time for radical action. Lancet 2019; 394: 261-272.

6. Petersen PE, Bourgeois D, Ogawa H, Estupinan-Day $S$, Ndiaye $C$. The global burden of oral diseases and risks to oral health. Bull World Health Organ 2005; 83: 661-669.

7. Freeman R, Doughty J, Macdonald M E, Muirhead V. Inclusion oral health: Advancing a theoretical framework for policy, research and practice. Community Dent Oral Epidemiol 2020; 48: 1-6.

8. Withers M, Browner C H, Aghaloo T. Promoting volunteerism in global health: Lessons from a medical mission in northern Mexico. J Community Health 2013; 38: 374-384

9. Asgary R, Junck E. New trends of short-term humanitarian medical volunteerism: Professional and ethical considerations. J Med Ethics 2013; 39: 625-631.

10. Caldron P H, Impens A, Pavlova M, Groot W. A systematic review of social, economic and diplomatic aspects of short-term medical missions. BMC Health Serv Res 2015; 15: 380

11. Roucka T M. A look at international, short-term service trips: Challenges from a dental ethical perspective. J Am Coll Dent 2014; 81: 21-27.

12. Friedman A, Loh L, Evert J. Developing an ethical framework for short-term international dental and medical activities. J Am Coll Dent 2014; 81: 8-15.

13. Holmgren C, Benzian H. Dental volunteering - a time for reflection and a time for change. Br Dent J 2011; 210 513-516.

14. Benzian $H$, van Palenstein Helderman W. Dental charity work-does it really help? Br Dent J 2006; 201: 413

15. van Helderman W P, Benzian H. Implementation of a Basic Package of Oral Care: Towards a reorientation of dental Ngos and their volunteers. Int Dent J 2006; 56: 44-48.

16. Patel J, Hearn L, Slack-Smith L M. Oral health care in remote Kimberley Aboriginal communities: The characteristics and perceptions of dental volunteers. Aust Dent J 2015: 60: 328-335.

17. Doughty J, Johnson A, Tatari A et al. A pilot denture service collaboration between Den-Tech denture charity and Crisis at Christmas Dental Service (CCDS): A PlanDo-Study-Act analysis. Br Dent J 2020; 228: 183-190.

18. Wilkinson $\mathrm{B}, \mathrm{McCool} \mathrm{J}$, Bois $\mathrm{G}$. Voluntourism: an analysis of the online marketing of a fast-growing industry. Int J Commun Health 2014; 4: 10-15.

19. Bohnert M. A student's perspective on the ethics of international charity dental care. J Am Coll Dent 2014; 81: $28-30$

20. Crozier R. Dental volunteering: An invaluable experience. Br Dent J 2018; 224: 393.

21. Goodman L A. Snowball Sampling. Ann Math Statist 1961; 32: 148-170.

22. McMahon S A, Winch P J. Systematic debriefing after qualitative encounters: An essential analysis step in applied qualitative research. BMJ Glob Health 2018; DOI: 10.1136/bmjgh-2018-000837.

23. Baker SE, Edwards R, Doidge M. How many qualitative interviews is enough? Expert voices and early career reflections on sampling and cases in qualitative research. Southampton: National Centre for Research Methods, 2012.

24. Charmaz K, Belgrave LL. Thinking about data with grounded theory. Qualitative Inquiry. 2019 Oct; 25(8) 743-53.

25. Kilanowski J F. Breadth of the Socio-Ecological Model. J Agromedicine 2017; 22: 295-297.

26. Bjerneld $M$, Lindmark G, McSpadden L A, Garrett M J. Motivations, concerns, and expectations of Scandinavian health professionals volunteering for humanitarian assignments. Disaster Manag Response 2006; 4: 49-58.

27. Clary E G, Snyder M, Ridge R D et al. Understanding and assessing the motivations of volunteers: A functional approach. J Pers Soc Psychol 1998; 74: 1516-1530.

28. Woods J E, Kiely J M. Short-term international medical service. Mayo Clin Proc 2000; 75: 311-313.

29. Batti R C. Challenges Facing Local NGOs in Resource Mobilization. Human Soc Sci 2014; 2: 57.

30. Huchko M J, Bukusi EA, Cohen C R. Building capacity fo cervical cancer screening in outpatient HIV clinics in the Nyanza province of western Kenya. Int J Gynaecol Obstet 2011: 114: 106-110.

31. Donaldson L, Philip P. Patient safety - a global priority. Bull World Health Organ 2004; 82: 892

32. Green T, Green H, Scandlyn J, Kestler A. Perceptions of short-term medical volunteer work: A qualitative study in Guatemala. Global Health 2009; 5: 4.

33. Varghese G K. A Practical Guide to the Management of Impacted Teeth. New Delhi: Jaypee Brothers Pvt. Ltd, 2010.

34. Kolokythas A, Miloro M (eds). Management of complications in oral and maxillofacial surgery. Chichester: Wiley-Blackwell, 2012.

35. Bauer I. More harm than good? The questionable ethics of medical volunteering and international student placements. Trop Dis Travel Med Vaccines 2017; 3: 5.

36. Arefi P, Cardoso E, Azarpazhooh A. Reexamining dental outreach programmes: A model for local empowerment and sustainable development. J Am Dent Assoc 2020; 151 340-348.

37. Kay E J, Locker D. Is dental health education effective? A systematic review of current evidence. Community Dent Oral Epidemiol 1996; 24: 231-235.

This article is licensed under a Creative Commons Attribution 4.0 International License, which permits use, sharing, adaptation, distribution and reproduction in any medium or format, as long as you give appropriate credit to the original author(s) and the source, provide a link to the Creative Commons licence, and indicate if changes were made. The images or other third party material in this article are included in the article's Creative Commons licence, unless indicated otherwise in a credit line to the material. If material is not included in the article's Creative Commons licence and your intended use is not permitted by statutory regulation or exceeds the permitted use, you will need to obtain permission directly from the copyright holder. To view a copy of this licence, visit http://creativecommons.org/licenses/by/4.0.

(c) The Author(s) 2021 